\title{
Microstructural and Mechanical Properties of AZ31B/Graphene Nanocomposite Produced by Stir Casting
}

\author{
Ashish Kumar Srivastava*, Ambuj Saxena, Nagendra Kumar Maurya, Shashi Prakash Dwivedi \\ Department of Mechanical Engineering, G L Bajaj Institute of Technology and Management, Greater Noida 201306, UP, India
}

Corresponding Author Email: ashish.srivastava@glbitm.ac.in

https://doi.org/10.18280/rcma.310107

Received: 20 April 2020

Accepted: 11 October 2020

\section{Keywords:}

AZ31B alloy, metal matrix nanocomposites, mechanical properties, stir casting, graphene nanoparticles

\begin{abstract}
In the current scenario, the development of high strength and low weight material is the demand of the aerospace defence organizations. Magnesium alloy based composite has low density, good mechanical and physical properties. In this study, magnesium alloy AZ31B is used as reinforcement material and graphene nanoparticle is used as reinforcement material. Stir casting technique is used for the development of composite material. Three weight percentages i.e. $0.4 \%, 0.8 \%$ and $1.2 \%$ are used for the casting. The microstructural analysis is performed to validate the presence of graphene particles in the developed composite. Further mechanical properties such as tensile strength, hardness and toughness are evaluated. Experimental results confirm that GNPs particles are uniformly distributed into the matrix material. It was observed that due to the reinforcement of GNPs particles tensile strength of the material is improved by $31.17 \%$, hardness is improved about $46.9 \%$. However, the peak value of toughness is observed $12.6 \mathrm{Jule} / \mathrm{cm}^{2}$ in the matrix material, it decreases by increasing the $\mathrm{wt} \%$ of reinforcement particle and lowest value of toughness of $6.82 \mathrm{Jule} / \mathrm{cm}^{2}$ is observed in AZ31B/1.2\%GNP composite.
\end{abstract}

\section{INTRODUCTION}

Nowadays the demand for lightweight material is increasing in the automobile and aerospace industries [1-3]. Over the past decades, the aluminium-based composite materials were used for the automotive and aerospace application [4-7]. However, in the current scenario, the demand for the magnesium-based composite material is increasing rapidly due to superior mechanical and physical properties [8]. The density of magnesium is about two-third of the density of aluminium [9]. The castability and machinability of the magnesium-based composite are excellent. It exhibits superior damping properties [10].

Fabrication techniques play a vital role in the mechanical properties of the magnesium-based composites. Nowadays several techniques such as electromagnetic stir casting, stir casting technique, friction stir processing, squeeze casting, vacuum casting etc. are used for the development of magnesium-based composite [11]. The mechanical properties of the magnesium are relatively poor. Various studies have been conducted related to the effect of reinforcement of ceramic particles on mechanical properties of magnesiumbased composites. The ceramic particles such as $\mathrm{TiB}_{2}, \mathrm{Al}_{2} \mathrm{O}_{3}$, $\mathrm{SiC}$, CNTs, Gr, GNPs were used by the researchers for the fabrication of magnesium-based composite material. Nguyen et al. [12] have evaluated the effect of ceramic particle i.e. $\mathrm{Al}_{2} \mathrm{O}_{3}$ on AZ31B allow. It was observed that the wear rate of the developed composite was reducing over the sliding speed. Nagaraj et al. [13] have developed AZX915/SiC composite to investigate the mechanical and wear properties. Results depicted that the excellent wear properties were observed at the reinforcement of $12 \% \mathrm{TiC}$ particle.

From archival literature, it can be concluded that several studies have been performed related to the effect of reinforcement of ceramic particles on mechanical and tribological properties of the magnesium-based composite. However, few studies have been found related to the effect of GNPs particles on AZ31B alloy. In this work, an attempt was made to evaluate the effect of GNPs wt.\% on mechanical properties of the magnesium composite.

\section{EXPERIMENTAL ANALYSIS}

This study deals with the effect of reinforcement of GNPs powder in magnesium alloy AZ31B on mechanical properties such as tensile strength, hardness, toughness. Further microstructural analysis was also performed to check the presence of GNPs particles in the developed composite. The chemical composition of AZ31Balloy is presented in Table 1. It has good thermal conductivity, good machinability and corrosion resistance properties. AZ31B is used for the manufacturing of lighter crafts and engine components. The physical properties and mechanical properties and of the AZ31B alloy are given in Table 2. Figure 1 shows the magnesium built used for the development of composite.

Table 1. Elemental composition of AZ31B

\begin{tabular}{ccccc}
\hline Elements & Mg & Al & Zn & Mn \\
\hline$\%$ & 96.5 & 2.6 & 0.7 & 0.2 \\
\hline
\end{tabular}


Table 2. Mechanical, Physical and Thermal properties of AZ31B

\begin{tabular}{cc}
\hline Properties & Value \\
\hline Tensile Strength & $253.85 \mathrm{MPa}$ \\
Yield Strength & $205 \mathrm{MPa}$ \\
Elastic Modulus & $48 \mathrm{GPa} \mathrm{GPa}$ \\
Poisson's Ratio & 0.35 \\
Shear Strength & $125 \mathrm{MPa}$ \\
Hardness & $49 \mathrm{HRB}$ \\
Elongation & $13 \%$ \\
Density & $1.71 \mathrm{~g} / \mathrm{cm}^{3}$ \\
\hline
\end{tabular}

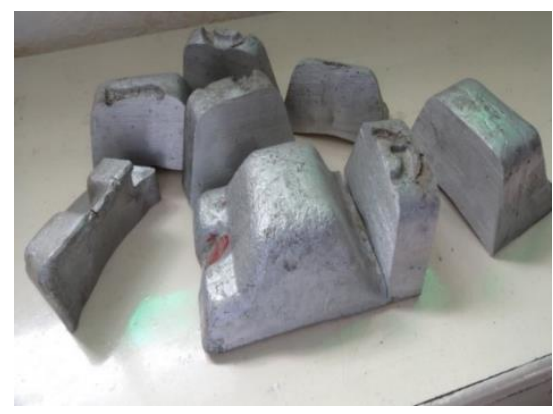

Figure 1. Magnesium AZ31B billets used for the procedure

Graphene is an allotrope of carbon and it is found in nature, graphene is a single atomic layer of graphite. In this work, Graphene-L of size $20 \mu \mathrm{m}$ was used. For the development of MMCs, a stir casting setup is used. Figure 2 shows the images of the complete setup with all the necessary equipment required. Sand crucibles are used to melt raw magnesium billets and to preheat the GNPs. Different crucibles are used to melt different magnesium combinations. For stir casting setup, the stirrer is welded to a long stainless-steel rod whose second end is connected to a motor. Motor controls the stirring speed and the motor's speed was controlled by a regulator. The blades of stirrer are made of steel so that it won't get melt.

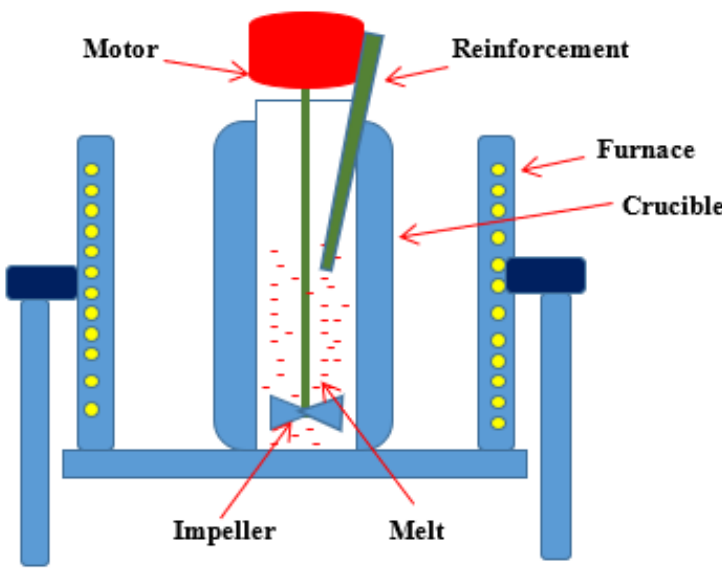

Figure 2. Line digram of stir casting setup

AZ31B is used as the matrix material and GNPs are taken as the reinforcement. The magnesium billet plates are heated in an electric resistance furnace at a temperature of 800 to $850^{\circ} \mathrm{C}$. GNPs powder is preheated at a temperature of $300^{\circ} \mathrm{C}$ for 15 to 20 minutes to remove the moisture content. After melting the AZ31 alloy mechanical stirrer starts stirring to form the vortex and reinforcement particles are gradually poured into the molten pool of the material. The stirring speed is kept around $350 \mathrm{rpm}$ to mix the GNPs particles into the matrix material. This process was continued for 10 minutes. Due to the stirring, the GNPs powder is uniformly dispersed into the matrix material. Three wt.\% of GNPs powder viz., $0.4 \%, 0.8 \%$ and $1.2 \%$ was used for the development of MMCs samples. To check the presence of GNPs reinforcement into the developed composite material, the microstructural examination has been conducted. The samples for microstructural examination were prepared as per ASTM E395 standards. The preparations of samples for microstructural examination conducted through different operations are shown in Figure 3. Microstructural images were taken from the LeicaDMI3000M inverted optical microscope.

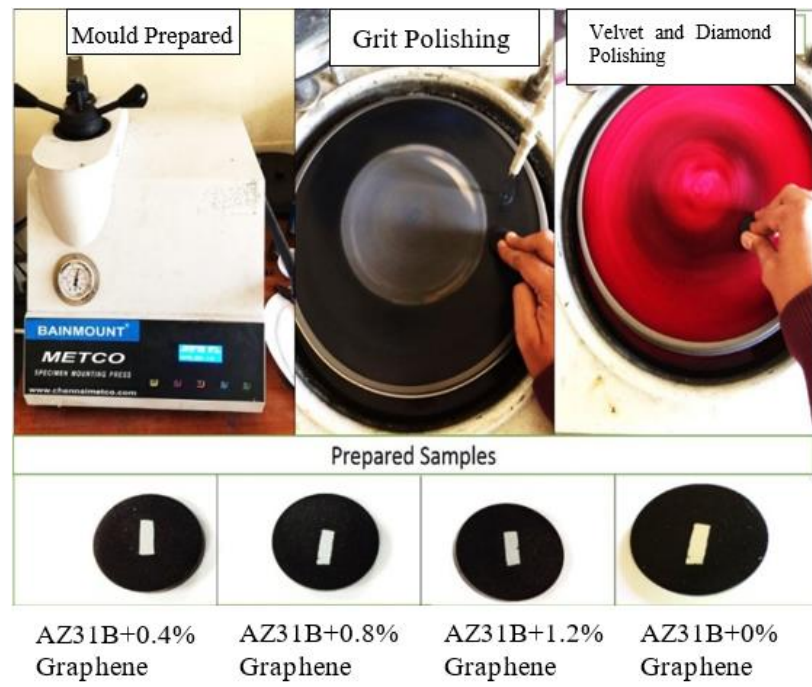

Figure 3. Sample preparation for microstructural examination of AZ31/GNPs

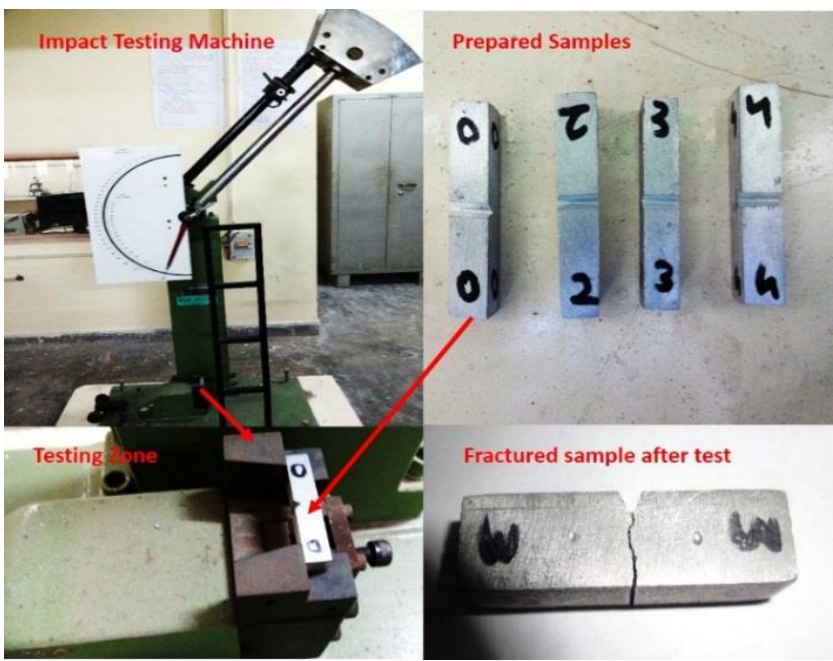

Figure 4. Experimental setup for the Charpy test

For the evaluation of tensile strength of the casted composite test samples were prepared as per the ASTM E-8 standards. Test samples were prepared in the rectangular shape. The tensile testing machine model TKG-EC-50KN was used to perform the tensile test of the specimen. ASTM A370 standard was used for the sample preparation of Charpy impact test from the fabricated composite. The specimen size used for the Charpy test was $10 \mathrm{~mm} \times 10 \mathrm{~mm} \times 55 \mathrm{~mm}$ having a notch (V-notch: $2 \mathrm{~mm}$ deep, with a $45^{\circ}$ angle and $0.25 \mathrm{~mm}$ radius). Figure 4 shows the experimental test setup for the Charpy test. Rockwell hardness tester was used to measure the hardness of 
the fabricated samples. The dimensional details of the hardness test specimens are $15 \mathrm{~mm} \times 10 \mathrm{~mm} \times 6 \mathrm{~mm}$. The experimental setup for the hardness test is shown in Figure 5. TRSN Series machine was used for the hardness test.

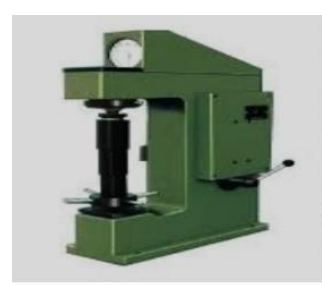

Hardness Tester

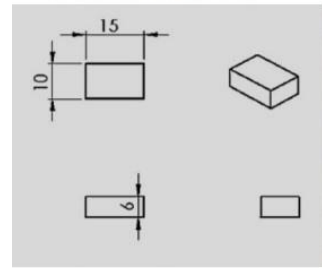

Specimen Size

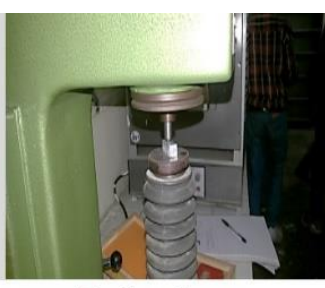

Testing Zone

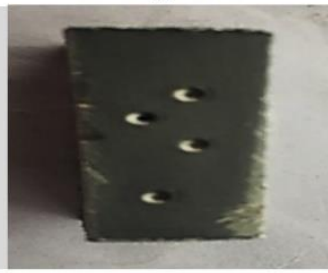

Tested Specimen
Figure 5. Hardness test specimen and Testing zone

\section{RESULT AND DISCUSSION}

Magnesium alloy based composite has been successfully developed by using GNPs as reinforcement. The MMCs were developed by varying the reinforcement percentage. The percentage of reinforcement material used in this study was $0.4 \%, 0.8 \%$ and $1.2 \%$. The optical microscopic images of developed nanocomposites are presented in Figure 6. It can be observed that the GNPs particles are uniformly distributed in the developed composite. The tensile test of with and without the reinforcement of specimen samples has been conducted. The value of yield strength, elongation at break and ultimate tensile strength is given in Table 3. The load stress-strain curve for fabricated samples is presented in Figure 7 to Figure 10.

It can be concluded that the tensile strength of the developed composite materials is increasing by increasing the reinforcement percentage of the GNPs particles. Figure 11 shows the effect of reinforcement percentage of the tensile strength of the material. The peak value of ultimate tensile strength was observed $333.68 \mathrm{MPa}$ with the reinforcement of $1.2 \%$ GNP particle. The presence of ceramic particles restricts the plastic flow of the material $[14,15]$, due to this the tensile strength of the material is increased. However, it was also observed from the stress-strain graph that the percentage elongation of the material was decreased due to the addition of reinforcement particles. Figure 12 shows the effect of reinforcement particles on percentage elongation of the developed MMCs. The peak value of percentage elongation was observed in the AZ31B alloy of $11.29 \%$ and lowest value of percentage elongation was observed about $9.21 \%$ in the specimen of AZ31/ 1.2 wt.\% GNP specimen sample

Table 3. Tensile test results of AZ31B-GNPnanocomposites

\begin{tabular}{ccccccc}
\hline S. No & MMCs & $\begin{array}{c}\text { Yield stress } \\
\left(\mathbf{N} / \mathbf{m m}^{\mathbf{2}}\right)\end{array}$ & $\begin{array}{c}\text { Elongation at } \\
\text { peak }(\mathbf{m m})\end{array}$ & $\begin{array}{c}\text { Tensile } \\
\text { Strength } \\
\left(\mathbf{N} / \mathbf{m m}^{\mathbf{2}}\right)\end{array}$ & $\begin{array}{c}\text { Hardness } \\
(\mathbf{H R B})\end{array}$ & $\begin{array}{c}\text { Toughness } \\
\mathbf{J u l l e}^{\mathbf{c}} \mathbf{\mathbf { c m } ^ { 2 }}\end{array}$ \\
\hline 1 & AZ31B & 205.0 & 11.29 & 253.85 & 49 & 12.6 \\
2 & AZ31B/0.4\% GNP & 242.4 & 10.20 & 315.13 & 52 & 10.42 \\
3 & AZ31B/0.8\% GNP & 248.6 & 9.53 & 320.88 & 66 & 7.64 \\
4 & AZ31B/1.2\% GNP & 257.5 & 9.21 & 333.68 & 72 & 6.82 \\
\hline
\end{tabular}
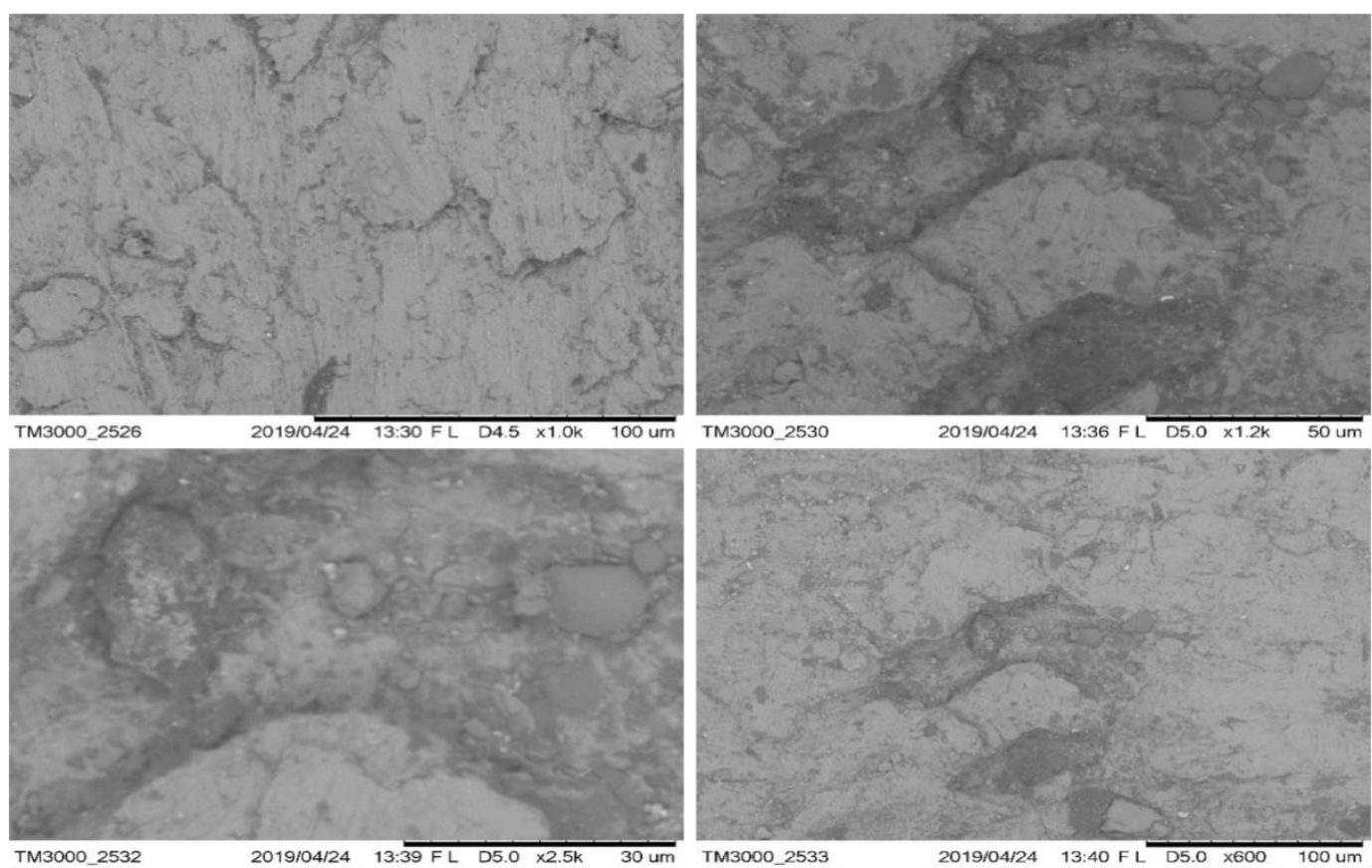

Figure 6. Microscopic images of developed MMCs 


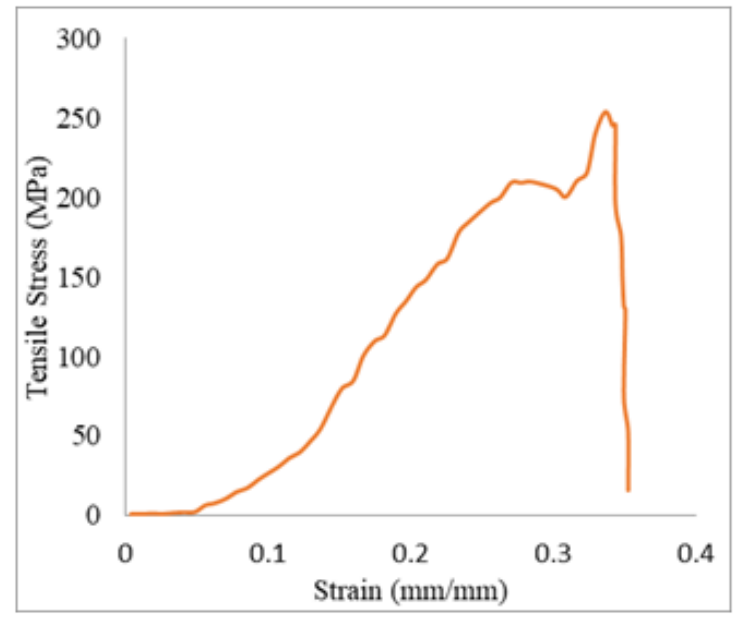

Figure 7. Stress versus strain curve of AZ31B alloy

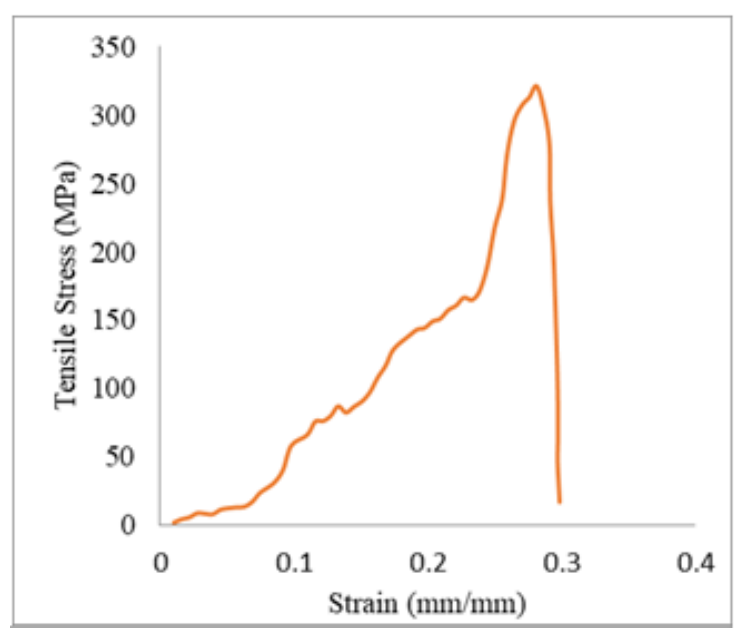

Figure 9. Stress versus strain curve of AZ31B/ 0.8\% GNP

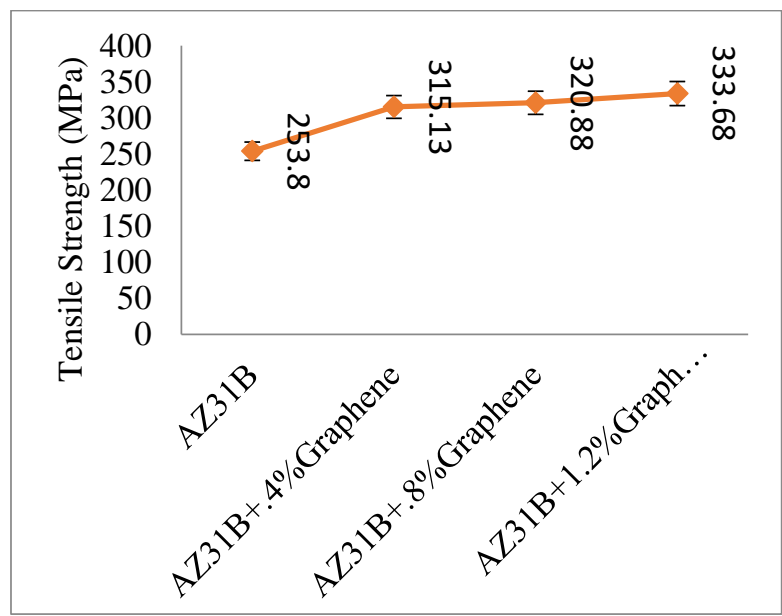

Figure 11. Variation of ultimate tensile strength versus GNP percentage

Figure 13 shows the influence of GNPs particle reinforcement on the hardness of the prepared MMCs. The lowest value of hardness $49 \mathrm{HRB}$ was observed in the specimen of AZ31B alloy. Results depicted that the value of hardness was significantly improved due to the reinforcement of GNPs particles. The peak value of hardness was found to be $72 \mathrm{HRB}$ in the specimen of AZ31B/ $1.2 \%$ of GNP. A similar

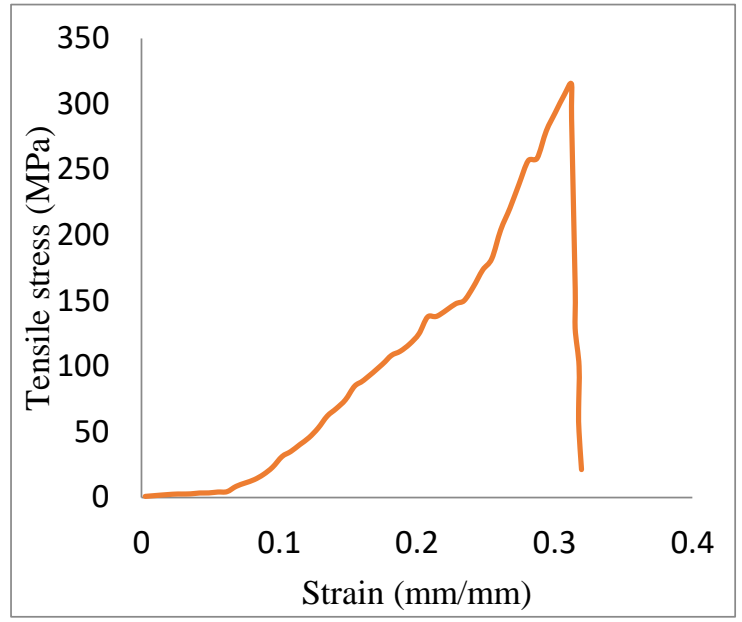

Figure 8. Stress versus strain curve of AZ31B/ 0.4\% GNP

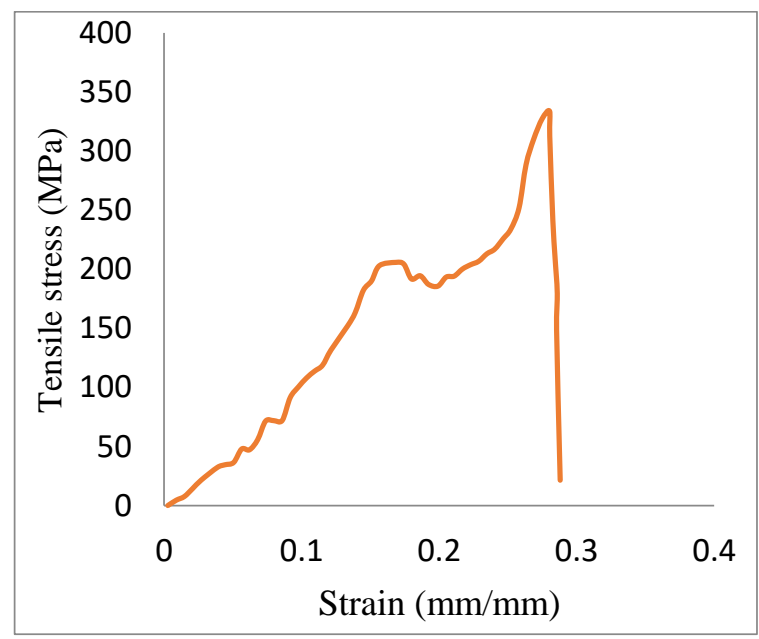

Figure 10. Stress versus strain curve of AZ31B/ 1.2\% GNP

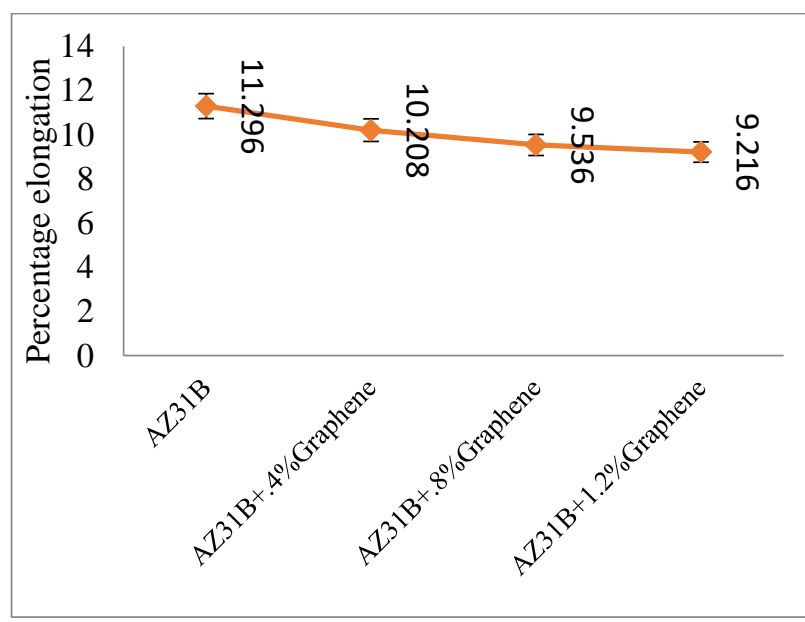

Figure 12. Elongation at peak versus GNP percentage

effect of reinforcement of ceramic particles in AZ31 material was observed by the other researchers also [16].

Figure 14 shows the results of the influence of GNPs particle reinforcement on the impact strength of the developed MMCs. It was observed that the value of impact strength of the material is decreased by the increase of reinforcement percentage because ductility of the material is decreased by the 
addition of ceramic particles into the AZ31 matrix material. The peak value of impact strength was found to be $12.6 \mathrm{~J} / \mathrm{cm}^{2}$ in the specimen of the AZ31 matrix material. The lowest value of impact strength was found to be $6.82 \mathrm{~J} / \mathrm{cm}^{2}$ in the specimen of AZ31/1.2\% GNP MMCs.

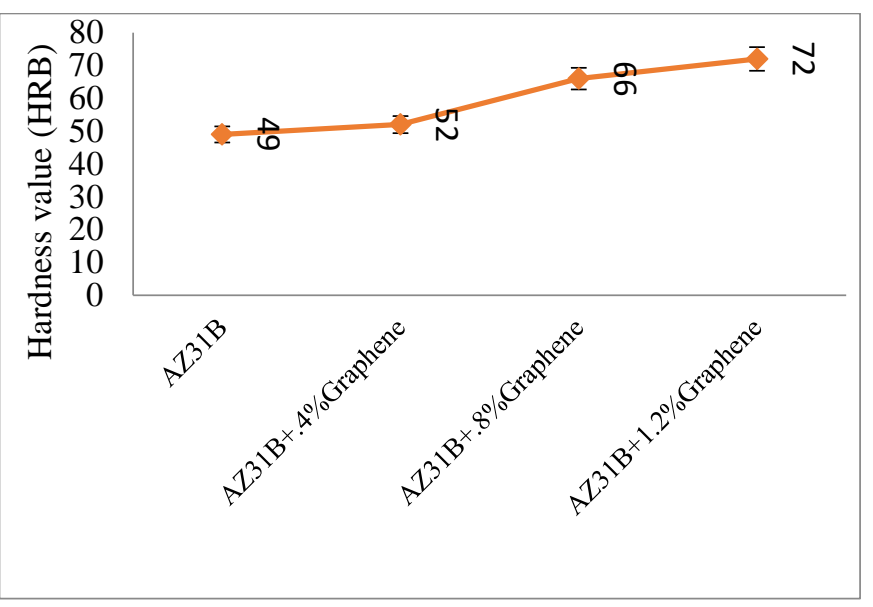

Figure 13. Hardness versus GNP percentage

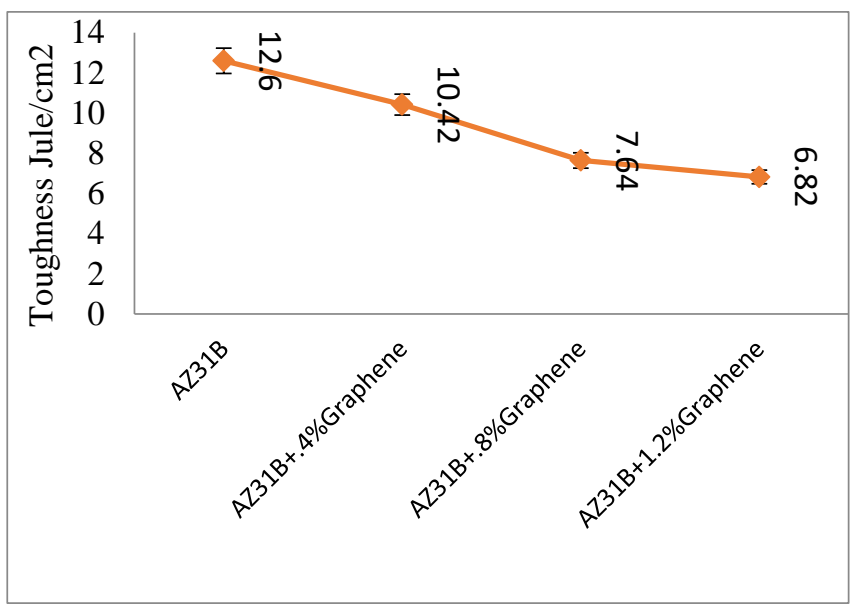

Figure 14. Toughness versus GNP percentage

\section{CONCLUSION}

In this study, the metal matrix composite of AZ31/GNPs was successfully cast through stir casting technique. Further mechanical properties of the casted composite have been evaluated. The following conclusion can be drawn from this work:

- Stir casting technique is a suitable process for the development of magnesium-based metal matrix composite.

- Tensile strength of the developed MMCs was increased due to the reinforcement of GNPs particles into the matrix AZ31B material. The peak value of tensile strength was found to be $333.68 \mathrm{MPa}$ in the specimen of AZ31B/1.2wt.\% GNP composite.

- The hardness of the fabricated MMCs was increased by the addition of GNPs particles. The peak value of hardness was observed $72 \mathrm{HRB}$ in the specimen of AZ31B/1.2wt.\% GNP composite whereas the lowest hardness of $49 \mathrm{HRB}$ was observed in the specimen of the AZ31 matrix material.

- The percentage elongation of the material is decreased by the increase of GNPs percentage. Percentage elongation of matrix material was observed maximum of $11.296 \%$ and lowest value of percentage elongation was found $9.21 \%$ in the specimen of AZ31B/1.2wt.\% GNP.

- Impact toughness was decreased by addition of GNPs particles into the matrix material. the value of toughness was found to be $12.6 \mathrm{~J} / \mathrm{cm}^{2}$ in the sample of matrix material whereas the toughness value was observed about $6.82 \mathrm{~J} / \mathrm{cm}^{2}$ in the specimen of AZ31/12.\% GNP MMCs.

- This study was limited to the effect of GNPs reinforcement only the presented methodology can be applied for the development of hybrid composite and the influence of other ceramic particles on the mechanical properties of magnesium-based composite material.

\section{REFERENCES}

[1] Dwivedi, S.P., Srivastava, A.K. (2020). Utilization of chrome containing leather waste in development of aluminium based green composite material. International Journal of Precision Engineering and ManufacturingGreen Technology, 7: 781-790. https://doi.org/10.1007/s40684-019-00179-1

[2] Srivastava, A.K., Sharma, B., Saju, B.R., Shukla, A., Saxena, A., Maurya, N.K. (2020). Effect of graphene nanoparticles on microstructural and mechanical properties of aluminum based nanocomposites fabricated by stir casting. World Journal of Engineering, 17(6): 859866. https://doi.org/10.1108/WJE-04-2020-0128

[3] Nag, A., Srivastava, A.K., Dixit, A.R., Mandal, A., Das, A.K., Tiwari, T. (2018). Surface integrity analysis of wire-EDM on in-situ hybrid composite $\mathrm{A} 359 / \mathrm{Al}_{2} \mathrm{O}_{3} / \mathrm{B}_{4} \mathrm{C}$. Materials Today: Proceedings, 5(11): 24632-24641. https://doi.org/10.1016/j.matpr.2018.10.261

[4] Tiwari, T., Sourabh, S., Nag, A., Dixit, A.R., Mandal, A., Das, A.K., Mandal, N., Srivastava, A.K. (2018). Parametric investigation on abrasive waterjet machining of alumina ceramic using response surface methodology. IOP Conf. Series: Materials Science and Engineering, 377: $\quad 012005 . \quad$ https://doi.org/10.1088/1757899X/377/1/012005

[5] Srivastava, A.K., Gupta, Y., Patel, S., Tiwari, S.K., Pandey, S. (2019). Metal matrix composites- a review on synthesis and characterization. IOP Conf. Series: Materials Science and Engineering, 691: 012077. https://doi.org/10.1088/1757-899X/691/1/012077

[6] Srivastava, A.K., Kumar, N., Dixit, A.R. (2021). Friction stir additive manufacturing - An innovative tool to enhance mechanical and microstructural properties. Materials Science and Engineering: B, 263: 114832. https://doi.org/10.1016/j.mseb.2020.114832

[7] Maurya, N.K., Maurya, M., Srivastava, A.K., Dwivedi, S.P., Kumar, A., Chauhan, S. (2019). Investigation of mechanical properties of Al 6061/SiC composite prepared through stir casting technique. Materials Today: Proceedings, 25(4): 755-758. https://doi.org/10.1016/j.matpr.2019.09.003

[8] Nouri, M., Li, D. (2017). Maximizing the benefit of aluminizing to AZ31 alloy by surface nanocrystallization for elevated resistance to wear and corrosive wear. Tribology International, 111: 211-219. https://doi.org/10.1016/j.triboint.2017.03.009

[9] Nouri, M., Sun, X., Li, D. (2013). Beneficial effects of 
yttrium on the performance of $\mathrm{Mg}-3 \% \mathrm{Al}$ alloy during wear, corrosion and corrosive wear. Tribology International, 67:

154-163.

https://doi.org/10.1016/j.triboint.2013.07.012

[10] Abbas, A., Huang, S.J., Ballokova, B., Sülleiova, K. (2020). Tribological effects of carbon nanotubes on magnesium alloy AZ31 and analyzing aging effects on CNTs/AZ31 composites fabricated by stir casting process. Tribology International, 142: 105982. https://doi.org/10.1016/j.triboint.2019.105982

[11] Srivastava, A.K., Maurya, N.K., Dixit, A.R., Dwivedi, S.P., Saxena, A., Maurya, M. (2020). Experimental investigations of A359/Si3N4 surface composite produced by multi-pass friction stir processing. Materials Chemistry and Physics, 257: 123717. https://doi.org/10.1016/j.matchemphys.2020.123717

[12] Nguyen, Q.B., Sim, Y.H.M., Gupta, M., Lim, C.Y.H. (2015). Tribology characteristics of magnesium alloy AZ31B and its composites. Tribology International, 82: 464-471. https://doi.org/10.1016/j.triboint.2014.02.024
[13] Nagaraj, M.C., Singh, H., Surappa, M.K. (2016). Correlation between microstructure and wear behavior of AZX915 Mg-alloy reinforced with $12 \mathrm{wt} \%$ TiC particles by stir-casting process. Journal of Magnesium and Alloys, 4(4): 306-313. https://doi.org/10.1016/j.jma.2016.09.002

[14] Shen, M.J., Wang, X.J., Li, C.D., Zhang, M.F., Hua, X.S., Zheng, M.Y., Wu, K. (2014). Effect of submicron size $\mathrm{SiC}$ particles on microstructure and mechanical properties of AZ31B magnesium matrix composites. Materials and Design, 54: 436-442. https://doi.org/10.1016/j.matdes.2013.08.078

[15] Kumar, T.S., Shalini, S., Ramu, M., Govindaraju, M. (2019). Characterisation of $\mathrm{AZ31/} \mathrm{ZrO} 2$ composites produced via stir casting. Materials Research Express, 6(11). https://doi.org/10.1088/2053-1591/ab4eae

[16] Huang, S.J., Abbas, A. (2019). Effects of tungsten disulfide on microstructure and mechanical properties of AZ91 magnesium alloy manufactured by stir casting. Journal of Alloys and Compounds, 817: 153321. https://doi.org/10.1016/j.jallcom.2019.153321 